\title{
Mannheim: An Example for the German Neuroradiology
}

\author{
L. Solymosi
}

Published online: 18 February 2012

(C) Springer-Verlag 2012

During the last 10 years, the German neuroradiology showed a huge progress. Not so long ago, there were only two chairs for neuroradiology in Germany, and in some federal states there were no independent departments of neuroradiology. Meanwhile many new chairs were established. Today, a department of neuroradiology is part of almost every university hospital in German cities including Mannheim.

The history of neuroradiology in Mannheim reflects the development of neuroradiology in Germany. Originating out of the neurologic clinic, the department was founded in 1977 by the lead consultant (Oberarzt) Prof. Klaus Tornow. During the previous years he had already been in charge of imaging in the still young university setting of the neurologic clinic. As in other places, during the first years, Prof. Tornow remained a member of the neurology department and also took part in on-call duty and lectures.

On 27 April 1978, the era of computed tomography started in Mannheim with the first cerebral scan. In 1979, a special neuroradiological section for pneumoencephalography, angiography and clinical X-ray ("MIMER") was created. Those first years were difficult. It was the time when neuroradiological departments consisted of single warriorsoccasionally supported by physicians-in-training-who were responsible for computed tomography, angiography and conventional imaging.
In Mannheim, Prof. Tornow was on his own right until his retirement in 1998. Final reporting of imaging acquired during the night or on weekends used to get delayed. After an interim appointment of Dr. Pöckler-Schönniger and Prof. Düber, on 1 February 2002, Prof. Cristoph Groden was appointed the new chair of neuroradiology, which was then an independent department with initially two consultants (Oberärzte) and four physicians-in-training.

The following years were devoted to setting up the department of diagnostic and interventional neuroradiology as well as successive introduction of after-hour services. The department currently comprises four assistant professors (habilitierte Oberärzte) and nine physicians-in-training. On 1 January 2010 an independent in-house on-call system was established. From this day onwards, the continuous availability of a CT, MRI and angiography service was secured in Mannheim.

Simultaneously, a scientific profile was developed. These attempts were acknowledged by the faculty, which in November 2005 led to the recognition as an independent department by the medical faculty in Mannheim. In this edition of the journal, an abstract of the scientific spectrum will be shown as original work.
L. Solymosi $(\varangle)$

Department of Neuroradiology, University Hospital Würzburg, Josef-Schneider-Str. 11, 97080 Würzburg, Germany

e-mail: solymosi@neuroradiologie.uni-wuerzburg.de 